\title{
Low-Carbon Operation of a Multi-Energy System with Hydrogen-Based Vehicle Applications
}

This paper was downloaded from TechRxiv (https://www.techrxiv.org).

\section{LICENSE}

CC BY 4.0

SUBMISSION DATE / POSTED DATE

23-11-2021 / 06-12-2021

\section{CITATION}

Mei, Jie; Lee, Christopher; Kirtley, James L. (2021): Low-Carbon Operation of a Multi-Energy System with Hydrogen-Based Vehicle Applications. TechRxiv. Preprint. https://doi.org/10.36227/techrxiv.17065364.v1

$\mathrm{DOI}$

10.36227/techrxiv.17065364.v1 


\title{
Low-Carbon Operation of a Multi-Energy System with Hydrogen-Based Vehicle Applications
}

\author{
Jie Mei ${ }^{1^{*}}$, Christopher H.T. Lee ${ }^{2}$, James L. Kirtley ${ }^{1}$ \\ ${ }^{1}$ Department of Electrical Engineering and Computer Science, Massachusetts Institute of Technology, Cambridge, MA, USA \\ ${ }^{2}$ School of Electrical and Electronic Engineering, Nanyang Technological University, Singapore \\ "jiemei@mit.edu
}

\begin{abstract}
In order to cope with the challenges of improving energy efficiency, increasing the integration of renewable energy, and achieving carbon emission reduction, multi-energy systems have received more and more attention in recent years and have been developing rapidly. Traditionally, different energy infrastructures are usually scheduled and operated independently, which leads to inefficient use of energy and waste of resources. By integrating into a multi-energy system, different energy infrastructures can be coupled and optimized into one unit. In this article, from a low-carbon point of view, the optimal scheduling of a real multi-energy system with hydrogen-based vehicle applications is proposed. The simulation results show that the proposed optimal scheduling can help quantify the daily operation cost and carbon emissions and achieve considerably operation cost saving and carbon reduction by reasonably arranging and utilizing all the devices in the system.
\end{abstract}

\section{Nomenclature}

\section{Variables}

$C_{a c} \quad$ Cooling power from absorption chiller

$C_{\text {carbon }}$

$C_{\text {energy }}$

$C_{e h p}$

$C_{d}$

$E_{c h p}$

$E_{d}$

$E_{\text {ehp }}$

$E_{p u}$

$E_{b s \_c h a}$

$E_{\text {bs_cha_com }}$

$E_{b s \_d i s}$

$E_{h s \_c h a}$

$E_{h s \_d i r}$

$R_{h s \_d i r}$

$R_{h s \_d i s}$

$E_{b s \_s t o r e d}$

$R_{b s \_s t o r e d}$

$R_{d}$

$G_{p u}$

$G_{a c}$

$G_{b}$

$G_{c h p}$

$H_{\text {chp }}$

$H_{e h p}$

$H_{b}$

$H_{d}$
Cost of carbon emission

Cost of energy purchased from power utility

Cooling power from EHP

Cooling power demand

CHP output electric power

Electric power demand

EHP input electric power

Electric power bought from power utility

BS total charging electric power

BS charging electric power from common bus

BS discharging electric power

HS charging electric power

HS input electric power for direct converting

HS direct conversion hydrogen power

HS discharging hydrogen power

BS stored electric energy

HS stored hydrogen energy

Hydrogen power demand from FCEVs

Natural gas bought from power utility

Chiller input natural gas

Boiler input natural gas

CHP input natural gas

Heating power from $\mathrm{CHP}$

Heating power from EHP

Heating power from boiler

Heating power demand
$I_{b s \_c h a} \quad$ BS binary charging mode indicator

$I_{b s \_d i s} \quad$ BS binary discharging mode indicator

$I_{h s_{-} c h a} \quad$ HS binary charging mode indicator

$I_{h s_{-} d i s} \quad$ HS binary discharging mode indicator

$I_{\text {ehp_c }} \quad$ EHP binary cooling mode indicator

$I_{\text {ehp }} h \quad$ EHP binary heating mode indicator

$S \quad$ Input solar power

$S_{\max } \quad$ Maximum available solar power

$t \quad$ Discrete time point

$\rho_{e} \quad$ Electricity unit price

$\rho_{g} \quad$ Natural gas unit price

Parameters

$C_{a c \_m a x} \quad$ Maximum cooling power from chiller

$C_{\text {ehp_max }} \quad$ Maximum cooling power from EHP

$E_{\text {chp_max }} \quad$ Maximum CHP output electric power

$E_{b s \_s t o r e d \_m a x}$ BS maximum capacity

$R_{h s_{-} \text {stored_max }}$ HS maximum capacity

$E_{b s \_c h a \_m a x}$ Maximum BS charging electric power

$E_{b s \_d i s \_\max }$ Maximum BS discharging electric power

$E_{h s_{-} \text {cha_max }}$ Maximum HS charging electric power

$R_{h s_{-} d i s_{-} \max } \quad$ Maximum HS discharging hydrogen power

$H_{\text {chp_max }} \quad$ Maximum CHP output heating power

$H_{\text {ehp_max }} \quad$ Maximum EHP output heating power

$H_{b_{-} \max } \quad$ Maximum boiler output heating power

$g_{b} \quad$ Coefficient of $\mathrm{CO}_{2}$ emission per $\mathrm{kWh}$ for boiler

$g_{c} \quad$ Coefficient of $\mathrm{CO}_{2}$ emission per $\mathrm{kWh}$ for Chiller

$g_{c h p} \quad$ Coefficient of $\mathrm{CO}_{2}$ emission per $\mathrm{kWh}$ for $\mathrm{CHP}$

$T \quad$ MES operation scheduling horizon

$\Delta T \quad$ Scheduling time interval 


$\begin{array}{ll}\eta_{a c} & \text { Chiller cooling-power-converting efficiency } \\ \eta_{b} & \text { Boiler heating-power-converting efficiency } \\ \eta_{c h p_{-} h} & \text { CHP heating power percentage } \\ \eta_{c h p_{-}} & \text {CHP electric power percentage } \\ \eta_{e h p_{-} h} & \text { EHP heating-power-converting efficiency } \\ \eta_{\text {ehp_c }} & \text { EHP cooling-power-converting efficiency } \\ \eta_{b s_{-} c h a} & \text { BS charging efficiency } \\ \eta_{b s_{-} d i s} & \text { BS discharging efficiency } \\ \eta_{h s_{-} c h a} & \text { HS charging efficiency } \\ \eta_{h s_{-} d i s} & \text { HS discharging efficiency } \\ \eta_{h s_{-} d i r} & \text { HS direct conversion efficiency } \\ \eta_{s} & \text { Solar inverter efficiency } \\ \rho_{c} & \text { Cost of carbon emission per ton }\end{array}$

\section{Introduction}

In the past few decades, due to the growing concerns of environmental problems and energy crisis, governments around the world have been committed to reducing dependence on fossil energy and carbon dioxide $\left(\mathrm{CO}_{2}\right)$ emissions and accelerating the development of renewable energy [1], [2]. As one of the main industries of energy consumption, the power industry accounts for about half of the total carbon dioxide emissions [3]. Therefore, the power industry has huge potential for carbon emission reduction. Low-carbon electricity is conducive to promoting a low-carbon economy [4].

In order to cope with the challenges of improving energy efficiency, increasing the integration of renewable energy, and achieving carbon emission reduction, multi-energy systems (MESs) composed of electric, natural gas, heat and other energy networks has received more and more attention in recent years and has been rapidly developed [5], [6]. Traditionally, different energy infrastructures in the system are usually planned and operated independently, which leads to lower energy use efficiency and waste of resources [7], [8]. Through integration as MES, defined as a system with multiple energy carriers that can be converted, adjusted and stored to meet energy demand, different energy infrastructures can be coupled and optimized into one unit [9]-[11].

Many researchers have done a collection of research on operation scheduling of MES. References [12], [13] take the combined cooling, heating and power (CCHP) technology into consideration in MES and construct a scheduling model with the lowest operating cost as the objective function. The authors in [14]-[16] proposed power flow management methods for MESs with integrated natural gas and electricity. A two-stage scheduling method for MES considering solar power forecasting based on random forest [17] is proposed in [18]. References [19], [20] adopted an integrated power and thermal energy system, including a detailed cogeneration model to efficiently accommodate more wind power. Mixed integer linear programming (MILP) model have been proposed to solve the optimal scheduling of MES operation in [21]-[25]. In [26], [27], evolutionary algorithm-based methods were proposed to solve the optimal scheduling and management of MES considering non-linear system characteristics. Some recent work has explored the advantages of demand response applications in MES operation [28]-[31].

The above-mentioned research on MES can be further improved from the following aspects: first, the cost of carbon emissions is not taken into account in daily scheduling. With the increasingly serious environmental pollution problem, low carbon is becoming an extremely important factor in MES scheduling. Second, hydrogen power is an important form of energy, especially for today's fuel cell electric vehicles (FCEVs), but it is hardly considered in these studies. Finally, most of them did not use real MES data for simulation, so they did not fully consider the physical characteristics and constraints of the devices in MES.

In this article, from the perspective of low-carbon operation, the optimal scheduling of a real MES (Stone Edge Farm in California, USA) is proposed, involving electricity, heating, cooling, and hydrogen energy. The optimal scheduling and management process is modeled as an optimization problem. In this regard, the low-carbon optimal operating point of the devices in the MES is calculated based on a cost-effective strategy.

There are three main contributions of this research: 1) This research takes into account the carbon emissions of MES and reduces the overall system carbon emissions based on economic methods. 2) In addition to the traditional battery storage system (BS) in MES, this study also considers the hydrogen storage system (HS) for FCEV applications. The existence of HS in MES can further effectively improve the flexibility of operation through the charging and discharging process. In addition, as FCEVs become more and more popular today, the research considering HS can also reflect the impact of FCEVs and related energy storage on MES. 3) Based on the actual collected MES data, the proposed optimal scheduling is analyzed and simulated, thus taking into account all the real MES component characteristics.

The rest of this paper is organized as follows. Section 2 describes the capabilities and operational constraints of the main devices in Stone Edge Farm MES to be analyzed. Section 3 introduces the modeling of system power flow diagram and MES operation optimal scheduling. The simulation results are given in Section 4, and finally the conclusions are drawn in Section 5.

\section{Stone Edge Farm MES}

In addition to lush landscapes, vast vineyards and world-class wines, the 16-acre Stone Edge Farm in Sonoma, California is also one of the world-class MES test beds. It is expected to showcase a variety of clean energy solutions that can be used to intelligently produce, consume, manage and store energy to reduce operating costs and carbon emissions, while supporting winery operations and meeting various power needs. Fig. 1 below shows an aerial view of Stone Edge Farm MES. Stone Edge Farm MES uses a complex optical fiber network to remotely monitor and control each device of the MES through the farm's Internet connection.

This section describes the main components in Stone Edge Farm MES, and their functions and operating constraints are for 
further analysis. The main components of the system include solar photovoltaic arrays (PVs), combined heat and power system (CHP), electric heat pump (EHP), absorption chiller, boiler, BS, HS, and load, which will be explained in detail in this section.

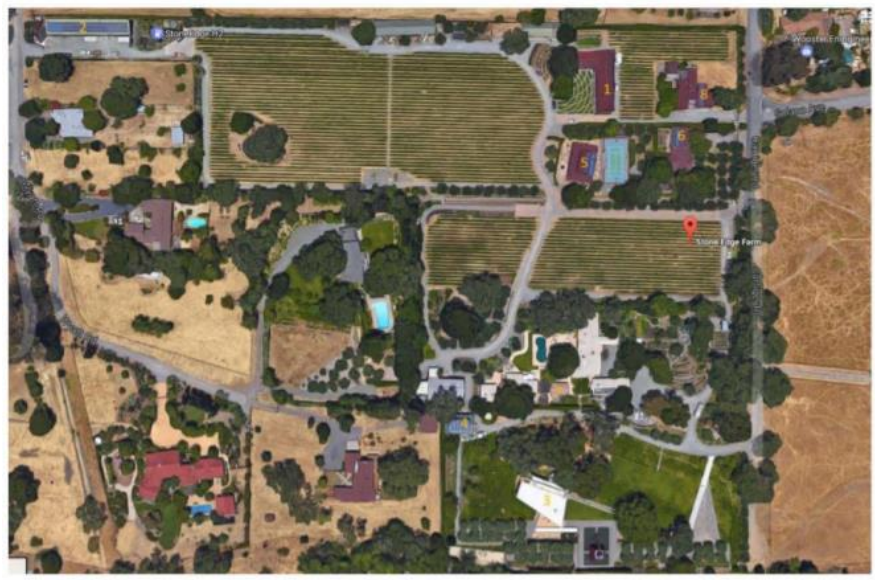

Fig.1 Aerial view of Stone Edge Farm MES, where the numbers are the locations of PVs [51].

\section{$2.1 \mathrm{CHP}$}

The electric and heating power system are coupled by CHP in Stone Edge Farm MES, which uses natural gas to generate electricity and heat. Since the local natural gas price is relatively lower than the electricity price, compared with EHP, if carbon emissions are not taken into consideration, CHP can meet heating and electricity demand at a lower cost.

The CHP in Stone Edge Farm MES is mainly driven by the Capstone gas turbine C65 gas variable external combustion engine. The Capstone gas turbine uses natural gas to generate electricity, and the waste heat of the turbine is the energy source of power generation to balance the heat load of the heating system. The efficiency of cogeneration is as high as $90 \%$. For the energy converted from natural gas, $68 \%$ is heat and $22 \%$ is electricity. Taking into account the limitations of CHP, the maximum output heating power is $52 \mathrm{~kW}$, and the maximum output electric power is $65 \mathrm{~kW}$, as shown in Eq. (1)-(2), which will be the maximum available heating and electric power at different time points of CHP for a given natural gas input. In some cases, a large amount of output electrical power is required while reaching the maximum output heating power limit. In this case, the part of the output heating power exceeding $52 \mathrm{~kW}$ will be discarded due to the output heating power limitation.

$$
\begin{aligned}
& 0 \leq H_{\text {chp }}(t) \leq \min \left\{G_{\text {chp }}(t) \cdot \eta_{\text {chp_h }}, H_{\text {chp_max }}\right\} \\
& 0 \leq E_{\text {chp }}(t) \leq \min \left\{G_{\text {chp }}(t) \cdot \eta_{\text {chp_e }}, E_{\text {chp_max }}\right\}
\end{aligned}
$$

\section{$2.2 P V s$}

Electricity is provided by the local power utility and on-site PVs. More than 500 solar photovoltaic panels are installed on the roofs of 8 buildings around the property, with a maximum output power of $130 \mathrm{~kW}$, converted to alternating current by
Enphase Energy M250 and S280 micro-inverters with an efficiency of $95 \%$. The power injected into the MES from the PVs needs to be less than the maximum available solar power at each point in time as in Eq. (3). In order to maintain the reliability of the system, the solar energy will be stored directly to the BS.

$$
0 \leq S(t) \leq S_{\max }(t) \cdot \eta_{s}
$$

\section{$2.3 E H P$}

Another main energy coupling device in MES is EHP, which can convert electrical energy into heating or cooling power. The EHP system with water supply Jandy Pro series Hi-E2 is used in Stone Edge Farm MES. The EHP system can generate up to $80 \mathrm{~kW}$ of heating power or up to $80 \mathrm{~kW}$ of cooling power. The corresponding efficiency of converting the received electric energy into output heating or cooling power is $95 \%$. Since EHP system cannot generate both heating and cooling power at the same time, this study uses binary variables $I_{e h p_{-} c}$ and $I_{e h p_{-} h}$ to represent the corresponding operating mode, and set constraints at different times, such as Eq. (4)-(7).

$$
\begin{gathered}
0 \leq H_{e h p}(t) \leq H_{e h p_{-} \max } \cdot I_{e h p_{-} h}(t) \\
0 \leq C_{e h p}(t) \leq C_{e h p_{-} \max } \cdot I_{e h p_{-} c}(t) \\
0 \leq I_{e h p_{-} h}(t)+I_{e h p_{-} c}(t) \leq 1 \\
E_{e h p}(t)=\frac{H_{e h p}(t)}{\eta_{e h p_{\_} h}}+\frac{C_{e h p}(t)}{\eta_{e h p_{-} c}}
\end{gathered}
$$

\subsection{Absorption Chiller}

The absorption chiller is an additional feature on the CHP capstone turbine system. The corresponding maximum output cooling power is $65 \mathrm{~kW}$, and the efficiency of converting the received natural gas into output cooling power is $80 \%$, as shown in Eq. (8)-(9).

$$
\begin{aligned}
& C_{a c}(t)=G_{a c}(t) \cdot \eta_{a c} \\
& 0 \leq C_{a c}(t) \leq C_{a c_{-} \max }
\end{aligned}
$$

\subsection{Boiler}

The boiler is another add-on feature equipped on the CHP capstone turbine system in Stone Edge Farm MES. The maximum output heating power is $80 \mathrm{~kW}$, and the efficiency of converting the received natural gas is $70 \%$, as shown in Eq. (10)-(11) below.

$$
\begin{aligned}
& H_{b}(t)=G_{b}(t) \cdot \eta_{b} \\
& 0 \leq H_{b}(t) \leq H_{b \_ \text {max }}
\end{aligned}
$$

\section{$2.6 B S$}

The main battery storage installed at Stone Edge Farm is Tesla Lithium-Ion batteries with a rated power of $250 \mathrm{~kW} / 475 \mathrm{kWh}$ [56]. This utility-scale battery consists of five $50 \mathrm{~kW} / 95 \mathrm{kWh}$ cabinet-and-rack units, each unit containing 16 individual lithium cobalt ion battery pods. The charging efficiency is $92 \%$, 
the maximum charging power is $250 \mathrm{~kW}$, the discharging efficiency is $90 \%$, and the maximum discharging power is $250 \mathrm{~kW}$, as shown in Eq. (12)-(16). In addition, since BS can only work in either charging or discharging mode, binary variables $I_{b s_{-} c h a}$ and $I_{b s_{-} d i s}$ are used in this work to constrain and indicate the corresponding operating states at different times.

$$
\begin{aligned}
& E_{\text {bs_stored }}(t+1)=E_{\text {bs_stored }}(t)+E_{b s_{-} c h a}(t) \cdot \Delta T \cdot \eta_{b s_{-} \text {ch }} \\
& -\left(E_{b s \_d i s} / \eta_{b s \_d i s}\right) \cdot \Delta T \\
& 0 \leq E_{b s_{-} c h a}(t) \leq E_{b s_{-} c h a \_m a x} \cdot I_{b s_{-} c h a}(t) \\
& 0 \leq E_{b s_{-} d i s}(t) \leq E_{b s_{-} d i s_{-} \text {max }} \cdot I_{b s_{-} d i s}(t) \\
& 0 \leq I_{b s_{-} \text {cha }}(t)+I_{b s_{-} d i s}(t) \leq 1 \\
& 0 \leq E_{\text {bs_stored }} \leq E_{\text {bs_stored_max }}
\end{aligned}
$$

\section{$2.7 H S$}

The HS of Stone Edge Farm is composed of Millennium Reign Energy Series 3 hydrogen storage and fueling station SHFA model 300. Hydrogen is produced from water through a hydrogen electrolyzer and is further stored in $241 \mathrm{~kg}$ red carbon fiber and steel tanks to power the Toyota Mirai FCEVs in the MES. Equivalent maximum HS capacity is $800 \mathrm{kWh}$, maximum charging power is $400 \mathrm{~kW}$, charging efficiency is $80 \%$, maximum discharge power is $400 \mathrm{~kW}$, and discharging efficiency is $80 \%$. A key function of the HS fueling station is to directly charge FCEVs with $80 \%$ efficiency and a limited capacity of $30 \mathrm{~kW}$ by converting electrical power, instead of using the stored hydrogen energy. In the same way, since HS can only work in either charging or discharging mode, binary variables $I_{h s_{-} c h a}$ and $I_{h s_{-} d i s}$ are used in this work to constrain and indicate the corresponding operating states at different times.

$$
\begin{aligned}
& R_{h s_{\_} s t o r e d}(t+1)=R_{h s_{-} s t o r e d}(t)+E_{h s_{-} c h a}(t) \cdot \Delta T \cdot \eta_{h s_{-} c h a} \\
& -\left(R_{h s_{-} d i s} / \eta_{h s_{-} d i s}\right) \cdot \Delta T \\
& 0 \leq E_{h s_{-} \text {cha }}(t) \leq E_{h s_{-} \text {cha_max }} \cdot I_{h s_{-} \text {cha }}(t) \\
& 0 \leq R_{h s_{-} d i s}(t) \leq R_{h s_{-} d i s_{-} \text {max }} \cdot I_{h s_{-} d i s}(t) \\
& 0 \leq I_{h s_{-} \text {cha }}(t)+I_{h s_{-} d i s}(t) \leq 1 \\
& 0 \leq R_{h s_{-} \text {stored }} \leq R_{\text {hs_stored_max }}
\end{aligned}
$$

\section{Modeling of MES optimal scheduling}

This section describes the modeling of Stone Edge Farm MES optimal scheduling. The power flow diagram of Stone Edge Farm MES, the coupling of electricity, natural gas, heating, cooling and hydrogen systems is shown in Fig. 2.

In a MES, the power coupling between power loads $\boldsymbol{D}$ and input power $\boldsymbol{P}$ can be linearly formulated using the coupling matrix $\boldsymbol{C}$ :

$$
\boldsymbol{D}=\boldsymbol{C P}
$$

In detail, for a MES with M-type of power loads and N-type of input power sources, Eq. (22) can be rewritten as Eq. (23):

$$
\left[\begin{array}{c}
D_{1} \\
D_{2} \\
\vdots \\
D_{m}
\end{array}\right]=\left[\begin{array}{cccc}
C_{11} & C_{12} & \cdots & C_{1 n} \\
C_{21} & C_{22} & \cdots & C_{2 n} \\
\vdots & \vdots & \ddots & \vdots \\
C_{m 1} & C_{m 2} & \cdots & C_{m n}
\end{array}\right]\left[\begin{array}{c}
P_{1} \\
P_{2} \\
\vdots \\
P_{n}
\end{array}\right]
$$

where $P_{n}$ and $D_{m}$ represent the n-th input power source and the m-th power load, respectively; the coefficient $C_{m n}$ represents the corresponding coupling factor. The coupling factor is a combination of the scheduling factors and efficiency factors, where the efficiency is determined by the characteristics of the energy converter device. The scheduling factor represents the operating status of the MES.

With power balance equations, MES power flow can be described. At the input side, the purchased natural gas is supplied to CHP, boiler, and absorption chiller, as in Eq. (24) and the power flows are drawn with green arrows in Fig. 2.

$$
G_{p u}(t)=G_{b}(t)+G_{a c}(t)+G_{c h p}(t)
$$

For the heating power balance, the boiler, CHP, and EHP meet the demand, as shown in Eq. (25), and the corresponding power flows are indicated by red arrows in Fig.2.

$$
H_{d}(t)=H_{b}(t)+H_{c h p}(t)+H_{e h p}(t)
$$

The cooling power demand is balanced through the chiller and EHP, as shown in Eq. (26), and the corresponding power flows in the diagram are drawn with light blue arrows.

$$
C_{d}(t)=C_{a c}(t)+C_{e h p}(t)
$$

The FCEVs' hydrogen power demand is provided by the HS discharge power and the direct conversion function in the HS as in Eq. (27). The hydrogen power flows in the system are marked with dark blue arrows in the Fig.2.

$$
R_{d}(t)=R_{h s_{-} d i s}(t)+R_{h s_{\_} d i r}(t)
$$

Eq. (28) represents the balance of electric power, where the input side includes the power from local distribution power utility, CHP and BS discharging, and the output side includes BS charging, HS charging, EHP, HS direct conversion and the demand. All the electric power flows in the MES are drawn with orange arrows in Fig. 2.

$$
\begin{aligned}
& \quad E_{d}(t)+E_{\text {ehp }}(t)+E_{h s_{-} c h a}(t)+\frac{R_{h s_{d i r}}(t)}{\eta_{h s_{d i r}}}+E_{\text {bs_cha_com }}(t)= \\
& E_{c h p}(t)+E_{\text {pu }}(t)+E_{\text {bs_dis }}(t)
\end{aligned}
$$

Finally, in the MES, in addition to the power input from the common bus, the power from the PVs is used to charge the BS, as shown in Eq. (29).

$$
E_{b s_{-} c h a}(t)=E_{b s_{-} c h a \_c o m}(t)+S(t)
$$

Minimizing the cost of purchased natural gas and electricity from local power utility and the cost of carbon emission within the scheduling horizon is treated as the objective function:

$$
C_{\text {total }}=C_{\text {energy }}+C_{\text {carbon }}
$$

$C_{\text {carbon }}=\rho_{c} \cdot\left[g_{b} \cdot \sum_{t \in T} G_{b}(t) \cdot \Delta T+g_{a c} \cdot \sum_{t \in T} G_{a c}(t) \cdot\right.$

$\left.\Delta T+g_{c h p} \cdot \sum_{t \in T} G_{c h p}(t) \cdot \Delta T\right]$ 


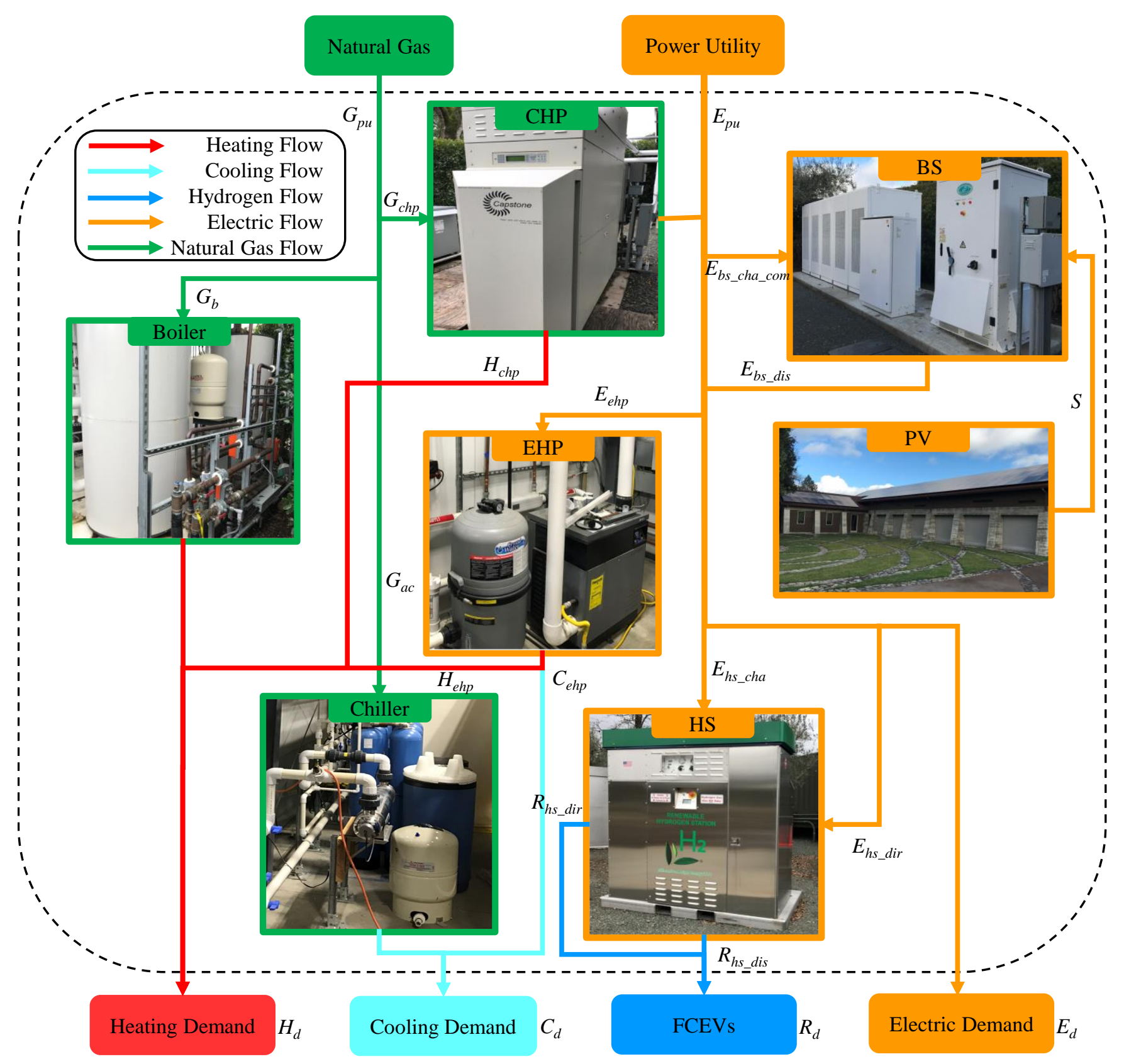

Fig.2 Power flow diagram of Stone Edge Farm MES

$C_{\text {energy }}=\sum_{t \in T} \rho_{e}(t) \cdot E_{p u}(t) \cdot \Delta T+\sum_{t \in T} \rho_{g}(t) \cdot G_{p u}(t) \cdot \Delta T$

Devices that consume natural gas, such as the absorption chiller, CHP, and the boiler, have lower energy costs than devices that consume electricity. But on the other hand, these devices also produce a large amount of $\mathrm{CO}_{2}$. Therefore, the cost of carbon emissions depends on the amount of $\mathrm{CO}_{2}$ produced by the operation of these natural gas-consuming devices.

The overall low-carbon optimal scheduling can be modeled as an optimization problem with minimizing Eq. (30) as the objective function and subject to the constraints of system devices in Eq. (1)-(21) and power balance in Eq. (24)-(29).

\section{Simulation results and analysis}

In this simulation, a typical 24-hour period, from 8 am on December 17, 2019, to 8 am on December 18, 2019, is firstly selected to demonstrate how the devices in the Stone Edge Farm is operated based on the proposed method. Then we will analyze the impact of the storages and PVs on the MES' operating cost and carbon emissions. All the system parameters are listed in Table 1 . The optimization problem is solved by MATLAB R2021a Optimization Toolbox.

Fig. 3 below shows the example 24-hour electric, cooling, heating, and hydrogen demands and available solar power. Since the local weather in California can be accurately predicted, the MES load demand is in big scale, and the demand 
response scheme can also be applied to the farm, here we assume that the uncertainty can be ignored, and the 24-hour power demands and the maximum available solar energy are known and accurate in this work. Fig.4 shows the local natural gas and electricity prices during this period. It can be seen from the figure that after changing the unit from thermo to $\mathrm{kWh}$, the local natural gas is relatively cheaper than electricity. The initial stored energy in BS and HS is set to zero.

Table 1 Stone Edge Farm MES operation parameters

\begin{tabular}{|c|c|}
\hline Parameter & Value \\
\hline$C_{a c \_\max }$ & $65 \mathrm{~kW}$ \\
\hline$C_{\text {ehp_max }}$ & $80 \mathrm{~kW}$ \\
\hline$E_{c h p \_m a x}$ & $65 \mathrm{~kW}$ \\
\hline$E_{b s \_s t o r e d \_m a x}$ & $475 \mathrm{kWh}$ \\
\hline$R_{h s \_s t o r e d \_m a x}$ & $800 \mathrm{kWh}$ \\
\hline$E_{b s \_c h a \_\max }$ & $250 \mathrm{~kW}$ \\
\hline$E_{b s \_d i s \_m a x}$ & $250 \mathrm{~kW}$ \\
\hline$E_{h s \_c h a \_m a x}$ & $400 \mathrm{~kW}$ \\
\hline$g_{b}$ & 0.22 \\
\hline$g_{c}$ & 0.09 \\
\hline$g_{c h p}$ & 0.61 \\
\hline$R_{h s_{-} d i s_{-} \max }$ & $400 \mathrm{~kW}$ \\
\hline$H_{\text {chp_max }}$ & $52 \mathrm{~kW}$ \\
\hline$H_{\text {ehp_max }}$ & $80 \mathrm{~kW}$ \\
\hline$H_{b \_\max }$ & $80 \mathrm{~kW}$ \\
\hline$T$ & 24 Hours \\
\hline$\Delta T$ & 0.5 Hours \\
\hline$\eta_{a c}$ & $80 \%$ \\
\hline$\eta_{b}$ & $70 \%$ \\
\hline$\eta_{c h p \_h}$ & $68 \%$ \\
\hline$\eta_{c h p \_e}$ & $22 \%$ \\
\hline$\eta_{e h p \_h}$ & $95 \%$ \\
\hline$\eta_{e h p \_c}$ & $95 \%$ \\
\hline$\eta_{b s \_c h a}$ & $92 \%$ \\
\hline$\eta_{b s \_d i s}$ & $90 \%$ \\
\hline$\eta_{h s_{-} c h a}$ & $80 \%$ \\
\hline$\eta_{h s_{-} d i s}$ & $80 \%$ \\
\hline$\eta_{h s_{-} d i r}$ & $80 \%$ \\
\hline$\rho_{c}$ & 51 \\
\hline
\end{tabular}

After the optimal scheduling method was run on the selected date, the detailed power flow and optimized scheduling of the MES with low operating cost and carbon emission was generated. In Fig.5, the cooling power generated to meet the corresponding cooling requirements was plotted. As can be seen from the figure, due to the lower cost of local natural gas, the cooling power of the chiller is preferred than that of the EHP. Only when the maximum cooling power generation capacity of the chiller is reached, the EHP starts to work in the cooling state to help meet the demand.

Similarly, the generated heating power that meets the demand was plotted in Fig. 6. Due to the high efficiency of cogeneration, CHP is given priority when heating power is needed. When CHP reaches its maximum heating power generation capacity, the boiler can generate the remaining required heat to help meet the demand. Compared with CHP and the boiler, EHP is the last choice for generating heat still because of the price disadvantage of local electricity.

Fig.7 depicts the generated hydrogen power to meet the corresponding demand. It can be seen from the figure that most of the required hydrogen was still met by the stored hydrogen energy in HS through discharging process. The remaining part of the demand is met by the direct converting function of HS.

Fig.8 shows the electric power output of CHP and BS discharging at different time points. It can be seen a large part of the electricity demand is met by CHP. Combining the 24hour energy storage curve of BS in Fig. 9, the electricity and natural gas purchased from the local power utility and the solar energy input to the system as in Fig. 10, it can be seen that one of the main functions of BS is to store solar energy during the day and use it at the night. Except for a few discharges, the BS is basically charged all the time during the day. Figure 9 also plots the hydrogen power stored in the HS during the 24 hours. Due to the FCEVs charging pattern, HS is scheduled to charge with enough energy during the day and discharge to power the FCEVs at night. The overall MES operating cost for this example 24-hour period is optimized to $\$ 483$ and $1,200 \mathrm{~kg} \mathrm{CO}_{2}$ generated from the devices.

In addition to the 24-hour case, based on the actual recorded data, the proposed method was applied to every day in December 2019 to explore the impact of energy storages and PVs on reducing operating costs and carbon emissions. Similarly, the initial stored energy in BS and HS is set to 0 , and the scheduling horizon is 24 hours starts from 8 each day. In Table 2 below, the operating costs and carbon emission with and without PV and storages are listed to show their economic and carbon emission advantages. For full system, the average daily operating cost for the month was $\$ 475$, and the average $\mathrm{CO}_{2}$ emission was $1,160 \mathrm{~kg}$. Without $\mathrm{HS}$, the average operating cost and $\mathrm{CO}_{2}$ emission would be $\$ 493$ and $1,201 \mathrm{~kg}$, respectively, suggesting an increase of $3.8 \%$ and $1.7 \%$. If there is no $\mathrm{PV}$ in the system, the cost and $\mathrm{CO}_{2}$ emission will increase to $\$ 582$ and $1,253 \mathrm{~kg}$, which is equivalent to an increase of $22 \%$ and $8 \%$, respectively. Finally, if there is no BS, the cost and $\mathrm{CO}_{2}$ emissions will be $\$ 605$ and $1,270 \mathrm{~kg}$ respectively, suggesting an increase of $27 \%$ and $10 \%$. The results can show the benefits of PVs and storages bring to the MES. With BS, the solar energy can be utilized to the greatest extent, because PVs are directly connected to BS. In addition, reasonable charge and discharge scheduling of storages can further reduce operating costs and $\mathrm{CO}_{2}$ emissions.

As summary, the proposed optimal scheduling can help quantify the daily operation cost and carbon emissions and achieve considerably operation cost saving and carbon reductions by reasonably arranging and utilizing all the devices in the system.

Table 2 Economic and carbon emission benefits of solar arrays and storages

\begin{tabular}{ccc}
\hline & Cost & $\mathrm{CO}_{2}$ \\
\hline Full system & $\$ 475$ & $1,160 \mathrm{~kg}$ \\
Without PVs & $\$ 582$ & $1,253 \mathrm{~kg}$ \\
Without BS & $\$ 605$ & $1,274 \mathrm{~kg}$ \\
Without HS & $\$ 493$ & $1,180 \mathrm{~kg}$ \\
\hline
\end{tabular}




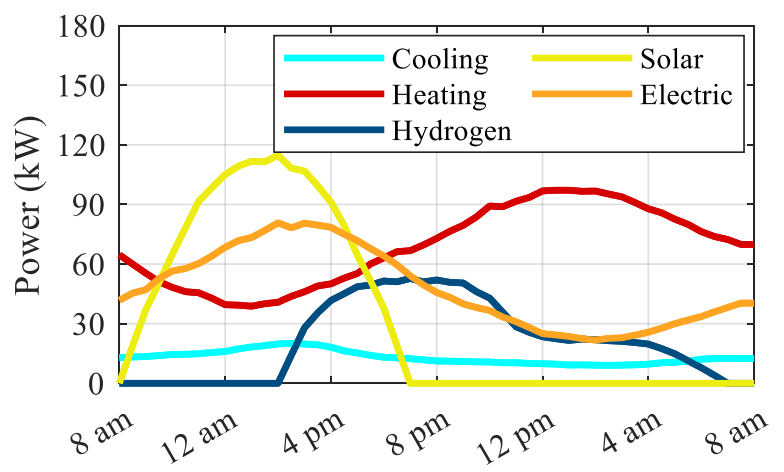

Time

Fig.3 Demands and available solar power for the example 24 hours

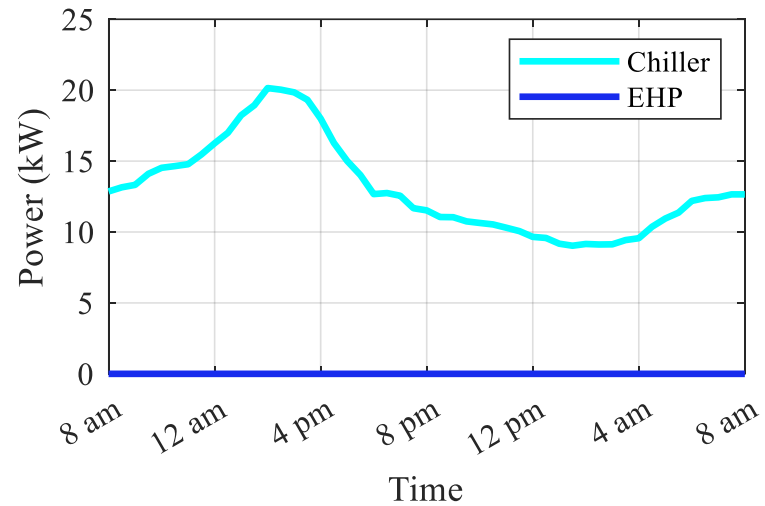

Fig.5 Generated cooling power for the example 24 hours

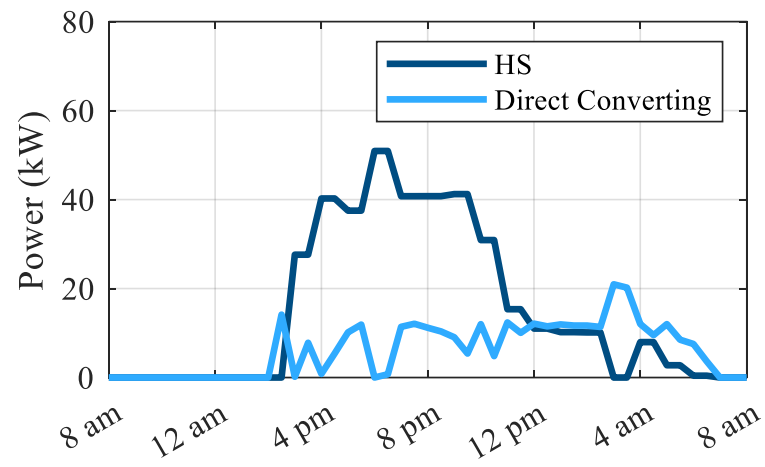

Time

Fig.7 Generated hydrogen power for the example 24 hours

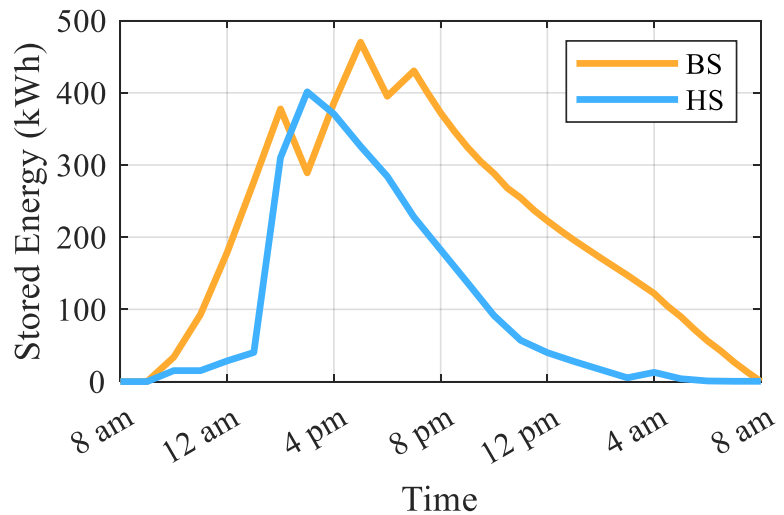

Fig.9 Stored energies for the example 24 hours

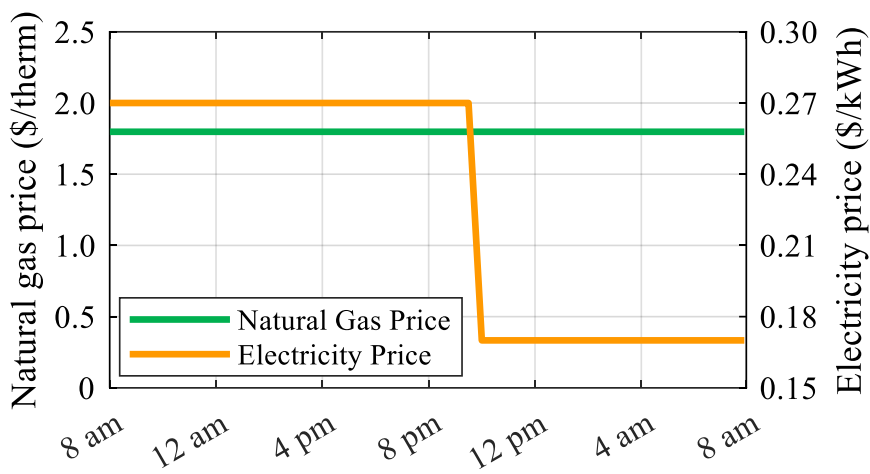

Time

Fig.4 Natural gas and electricity prices for the example 24 hours

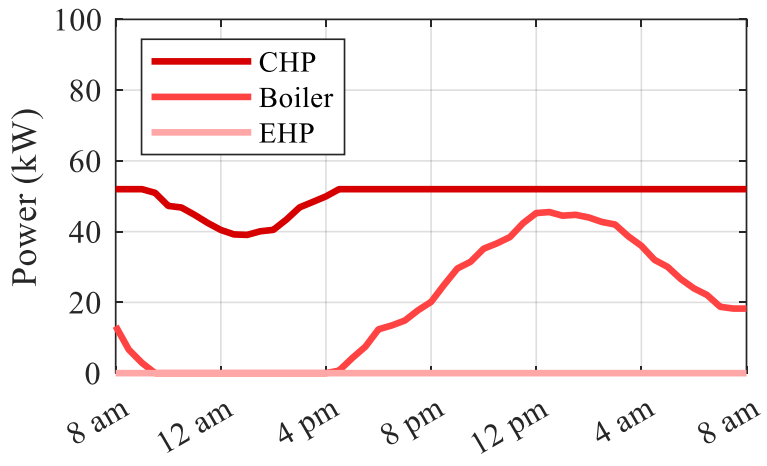

Time

Fig.6 Generated heating power for the example 24 hours

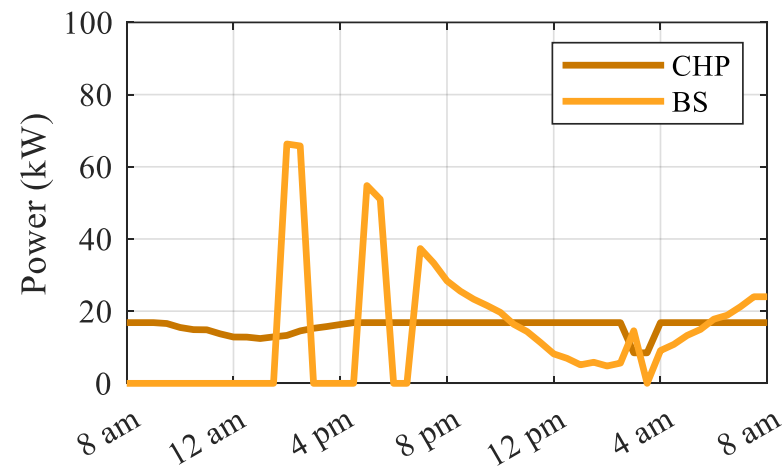

Time

Fig.8 CHP and BS output electric power for the example 24 hours

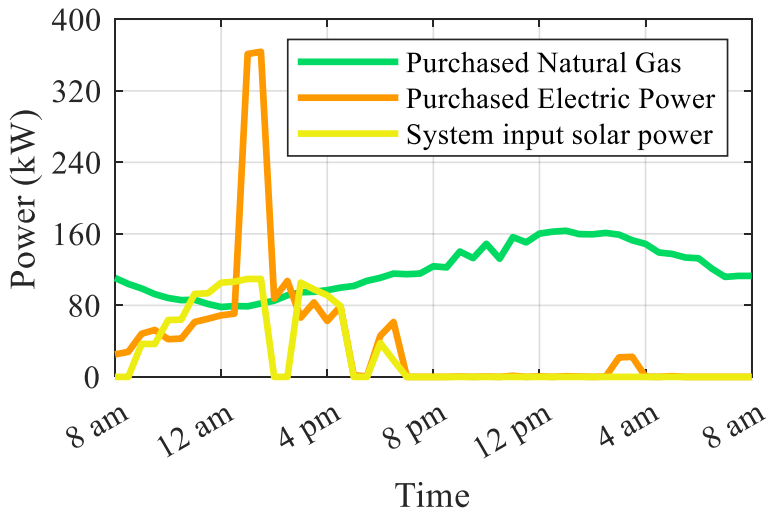

Fig.10 MES input power for the example 24 hours 


\section{Conclusion}

In this paper, from a low-carbon perspective, the optimal scheduling of a real multi-energy system with hydrogen-based vehicle applications is proposed. There are three main contributions of this work: 1) this research takes into account the carbon emissions of multi-energy system and reduces the overall system carbon emissions based on economic methods. 2) In addition to traditional battery storage systems in multienergy systems, this research also considers the applications of hydrogen storage for fuel cell electric vehicles. 3) The proposed method is simulated and analyzed based on the actual data collected from a real multi-energy system, Stone Edge Farm. Therefore, the characteristics of the real system are fully considered. The simulation results show that the proposed optimal scheduling can help quantify the daily operation cost and carbon emissions and achieve considerably operation cost saving and carbon emission reduction by reasonably arranging and utilizing all the devices in the system.

\section{References}

[1] Li, Y., Zou, Y., et al.: 'Optimal stochastic operation of integrated lowcarbon electric power, natural gas and heat delivery system', IEEE Trans. Sustain. Energy, 2017, 9, (1), pp. 273-283

[2] Li, N., Uçkun, C., Constantinescu, E.M., et al.: 'Flexible operation of batteries in power system scheduling with renewable energy', IEEE Trans. Sustain. Energy, 2016, 7, (2), pp. 685-696

[3] Xiong, L., Shen, B., et al.: 'The allowance mechanism of chinas carbon trading pilots: A comparative analysis with schemes in EU and California', Appl. Energy, 2017, 185, pp. 1849-1859

[4] Feng, Z., Tang, W., et al.: 'Bi-level allocation of carbon emission permits based on clustering analysis and weighted voting: A case study in China', Appl. Energy, 2018, 228, pp. 1122-1135

[5] Xu, X., Jin, X., Jia, H., et al.: 'Hierarchical management for integrated community energy systems', Appl. Energy, 2015, 160, pp. 231-243

[6] Pan, Z., Guo, Q., Sun, H.: 'Feasible region method based integrated heat and electricity dispatch considering building thermal inertia', Appl Energy, 2017, 192, pp. 395-407

[7] Li, G., Zhang, R., Jiang, T., et al.: 'Security-constrained bi-level economic dispatch model for integrated natural gas and electricity systems considering wind power and power-to-gas process', Appl. Energy, 2017, 194, pp. 696-704

[8] Geidl, M., Andersson, G.: 'Optimal power flow of multiple energy carriers', IEEE Trans. Power Syst., 2007, 22, (1), pp. 145-155

[9] Geidl, M., Andersson, G.: 'Optimal coupling of energy infrastructure'. Proc. IEEE Power Tech Conf., Lausanne, July 2007, pp. 1398-1403

[10] Geidl, M.: 'Integrated modeling and optimization of multi-carrier energy systems', Ph.D. thesis, Swiss Federal Institute of Technology Zurich, 2007

[11] Krause, T., Andersson, G., Frohlich, K., et al.: 'Multiple-energy carriers: modeling of production, delivery, and consumption', Proc. IEEE, 2011, 99, pp. 15-27

[12] Gu, W., Lu, S., et al.: 'Residential cchp microgrid with load aggregator: Operation mode, pricing strategy, and optimal dispatch', Appl. Energy, 2017, 205, pp. 173-186

[13] Ju, L., Tan, Z., et al.: 'Multi-objective operation optimization and evaluation model for cchp and renewable energy based hybrid energy system driven by distributed energy resources in China', Energy, 2016, 111, pp. 322-340

[14] Wu, L., Shahidehpour, M.: 'Optimal coordination of stochastic hydro and natural gas supplies in midterm operation of power systems', IET Gener. Transm. Distrib., 2011, 5, (5), pp. 577-587

[15] Chaudry, M., Jenkins, N., Qadrdan, M., et al.: 'Combined gas and electricity network expansion planning', Appl. Energy, 2014, 113, pp. 1171-1187

[16] Bai, L., Li, F., Cui, H., et al.: 'Interval optimization based operating strategy for gas-electricity integrated energy systems considering demand response and wind uncertainty',Appl. Energy, 2016, 167, pp.270-279

[17] Mei, J., He, D., Harley, R., et al.: 'A random forest method for realtime price forecasting in New York electricity market', 2014 IEEE PES General Meeting| Conference \& Exposition, 2014, Jul 27, pp. 1-5

[18] Mei, J., Zuo, Y., Lee, C., et al.: 'Stochastic optimization of multienergy system operation considering hydrogen-based vehicle applications', Advan. Appl. Energy, 2021, 2, 100031

[19] Chen, X., McElroy, M.B., et al.: 'Integrated energy systems for higher wind penetration in China: Formulation, implementation, and impacts', IEEE Trans. Power Syst., 2017, 33, (2), pp. 1309-1319

[20] Chen, X., Kang, C., et al: 'Increasing the flexibility of combined heat and power for wind power integration in China: Modeling and implications', IEEE Trans. Power Syst., 2014, 30, (4), pp. 1848-1857

[21] Wang, Y., Zhang, N., et al.: 'Mixed-integer linear programming-based optimal configuration planning for energy hub: Starting from scratch', Appl. Energy, 2018, 210, pp. 1141-1150

[22] Martelli, E., Freschini, M., et al.: 'Optimization of renewable energy subsidy and carbon tax for multi energy systems using bilevel programming', Appl. Energy, 2020, 267, pp. 115089

[23] Mei, J., Wang, X., Kirtley, J.L.: 'Optimal scheduling of real multicarrier energy storage system with hydrogen-based vehicle applications', IET Renewable Power Generation, 2020, 14, (3), pp. 381-388

[24] Moser, A., Muschick, D., et al.: 'A MILP-based modular energy management system for urban multi-energy systems: Performance and sensitivity analysis.', Appl. Energy, 2020, 261, pp. 114342

[25] Chen, C., Sun, H., et al.: 'Two-stage robust planning-operation cooptimization of energy hub considering precise energy storage economic model', Appl. Energy, 2019, 252, pp. 113372

[26] Mayer, M.J., Szilágyi, A., et al.: 'Environmental and economic multiobjective optimization of a household level hybrid renewable energy system by genetic algorithm', Appl. Energy, 2020, 269, pp. 115058

[27] Kampouropoulos, K., Andrade, F.: 'Multiobjective optimization of multi-carrier energy system using a combination of ANFIS and genetic algorithms', IEEE Trans. Smart Grid, 2016, 9, (3), pp. 2276-2283

[28] Pazouki, S., Haghifam, M.R.: 'Optimal planning and scheduling of energy hub in presence of wind, storage and demand response under uncertainty', Elsevier J. Electr. Power Energy Syst., 2016, 80, pp. 219 239

[29] Bahrami, S., Sheikhi, A.: 'From demand response in smart grid toward integrated demand response in smart energy hub', IEEE Trans. Smart Grid, 2016, 7, (2), pp. 650-658

[30] Li, X., Zhang, R., Bai, L., et al.: 'Stochastic low-carbon scheduling with carbon capture power plants and coupon-based demand response', Appl. Energy, 2018, 210, pp. 1219-1228

[31] Alipour, M., Zare, K., Abapour, M.: 'MINLP probabilistic scheduling model for demand response programs integrated energy hubs', IEEE Trans. Ind. Inf., 2018, 14, (1), pp. 79-88 